\title{
Research Article \\ Effect of Cement Asphalt Mortar Debonding on Dynamic Properties of CRTS II Slab Ballastless Track
}

\author{
Ping Wang, Hao Xu, and Rong Chen \\ MOE Key Laboratory of High-Speed Railway Engineering, Southwest Jiaotong University, Chengdu 610031, China \\ Correspondence should be addressed to Hao Xu; xhao0@163.com
}

Received 30 August 2013; Accepted 16 January 2014; Published 23 February 2014

Academic Editor: Jun Liu

Copyright (C) 2014 Ping Wang et al. This is an open access article distributed under the Creative Commons Attribution License, which permits unrestricted use, distribution, and reproduction in any medium, provided the original work is properly cited.

\begin{abstract}
The debonding of cement emulsified asphalt mortar (CA mortar) is one of the main damage types in China railway track system II slab ballastless track. In order to analyze the influence of mortar debonding on the dynamic properties of CRTS II slab ballastless track, a vertical coupling vibration model for a vehicle-track-subgrade system was established on the base of wheel/rail coupling dynamics theory. The effects of different debonding lengths on dynamic response of vehicle and track system were analyzed by using the finite element software. The results show that the debonding of CA mortar layer will increase the dynamic response of track. If the length of debonding exceeds $1.95 \mathrm{~m}$, the inflection point will appear on the vertical displacement curve of track. The vertical vibration acceleration of slab increases 4.95 times and the vertical dynamic compressive stress of CA mortar near the debonding region increases 15 times when the debonding length reaches $3.9 \mathrm{~m}$. Considering the durability of ballastless track, once the length of debonding reaches $1.95 \mathrm{~m}$, the mortar debonding should be repaired.
\end{abstract}

\section{Introduction}

China railway track system (CRTS) II slab ballastless track is a new type of track structure which is developed on the base of German's Burger slab ballastless track system. It has been widely used in the Beijing-Tianjin intercity railway and Beijing-Shanghai high-speed railway. The CRTS II slab ballastless track on the subgrade consists of rail, fastening system, track slab, cement emulsified asphalt mortar (CA mortar) layer, and concrete supporting layer. CA mortar layer, as a filling layer between track slab and concrete supporting layer, functions in supporting, load transfer, adjustment, and buffer action [1-5]. Field survey of Beijing-Shanghai highspeed railway shows that CA mortar layer of CRTS II slab ballastless track has broken away from the slab, the interface bonding strength has almost completely disappeared, and debonding between slab and CA mortar layer appeared. Figure 1 shows the phenomenon of debonding between slab and CA mortar layer of CRTS II slab ballastless track on field.

According to the analysis theory of spatial vibration of high-speed train and slab track system, Xiang et al. [6] studied the effect of voided slab induced by deteriorations of cement asphalt mortar layer, such as felt invalidation, dehiscence, embrittlement, and cataclasm, on vibration responses of the slab track. But there is no research report about effect of cement asphalt mortar disease on dynamic performance of CRTS II slab ballastless track. Xu and Cai [7] made the longitudinally connected ballastless track on earth subgrade as the research object and established a couple of dynamic models of train-longitudinally connected ballastless track on earth subgrade. The dynamic characteristics of track subjected to 300 and $350 \mathrm{~km} / \mathrm{h}$ running speeds of CRH2300EMU were analyzed. Song and Zhai [8] established the dynamic finite element model of the infrastructure above embankment for CRTS II slab ballastless track to analyze the dynamic stress distribution and transfer law of track and subgrade under the moving load at different speeds. According to the vehicle-track-subgrade interaction principle and finite element theory, Nan [9] established the dynamic finite element model of CRTS II slab ballastless track on subgrade and analyzed the vehicle safety and comfort and dynamic response of the track structure and subgrade. In addition, he studied the influence of fastener stiffness, mortar elastic modulus, and the supporting layer of elastic modulus on the ballastless track system. 

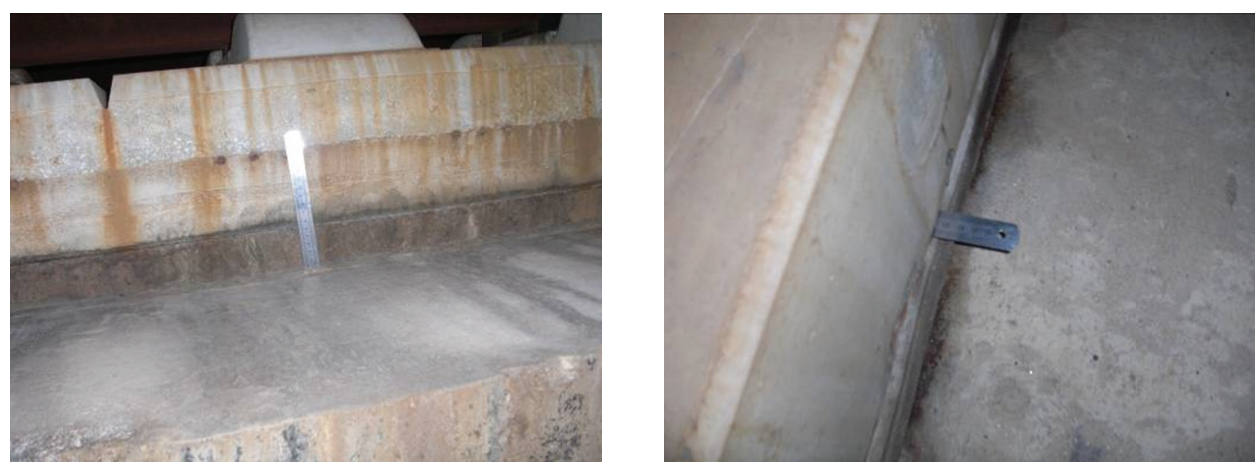

FIgURE 1: Debonding between slab and CA mortar layer of CRTS II slab ballastless track.

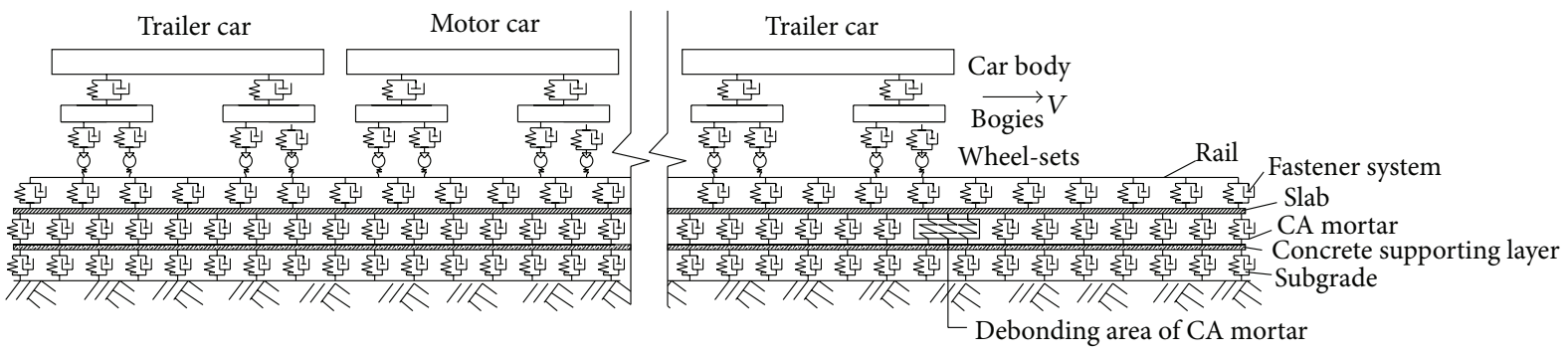

FIGURE 2: Vehicle-track-subgrade vertical coupling vibration plane model.

The deformation of track in subgrade is bigger than that of track in bridge and tube under the same train loading, because the foundation stiffness of subgrade is smaller than bridge and tube. Based on the wheel/rail coupling dynamics theory [10-13], this paper studied the effect of cement asphalt mortar disease on dynamic performance of CRTS II slab ballastless track.

\section{Mechanism of Mortar Deterioration}

CRTS II slab ballastless track is a kind of layered structure. It transmits the longitudinal, transverse, and vertical force by bond action between CA mortar layer and slab or concrete supporting layer. Bond failure between CA mortar layer and slab or concrete supporting layer is the cause of the emergence and development of mortar debonding.

The nature of bond between CA mortar layer and slab of CRTS II slab ballastless track is the interaction of contact interface, which is a complex physical and chemical process. It is a mechanical occlusion between CA mortar layer and slab in the macrolevel, and it is the adsorption, chemical bonding action, electrostatic attraction, and other composite actions after the molecular diffusion between CA mortar and concrete in the microlevel. Bond failure will occur at arbitrary weak position of contact interface between slab and CA mortar layer.

The debonding failure between slab and CA mortar layer is slip failure belonging to double materials interface bond failure, because the CRTS II slab ballastless track is a kind of layered structure. The chemical bonding and mechanical occlusion of bond interface decrease gradually under the temperature load. The debonding of bond interface will appear and the bond strength of bond interface cannot be restored after unloading. The mortar debonding will expand and mortar will be damaged in the beating action because of the high frequency vibration of track under repeated train loading after bond failure, which not only affects the smoothness, safety, and comfort of high-speed running, but also does not accord with the requirement of durability and reliability of high-speed railway.

\section{Model of Vertical Vehicle-Track-Subgrade and Calculation Method}

The debonding between CA mortar layer and slab affects mainly the vertical vibration of system, so this paper only considered the vertical vibration of vehicle, track, and subgrade. According to the wheel/rail system coupling dynamics theory [10-13], the vehicle-track-subgrade system vertical coupling vibration calculation model was established, which is shown in Figure 2. The total length of model is $780 \mathrm{~m}$ and vehicle model was simulated by 6 motor cars and 2 trailer cars. Track was simulated by three-layer point-supported beam model which considered rail, slab, and concrete supporting layer. The rail, slab, and concrete supporting layer were simulated by Euler beam elements. The fastening systems were simulated by linear spring-damping elements. Under the assumption that the CA mortar layer along the transverse of slab debonded completely, the CA mortar layer was simulated by linear spring and damping elements to connect the slab and concrete supporting layer. The CA mortar layer in debonding area was simulated by nonlinear spring elements 


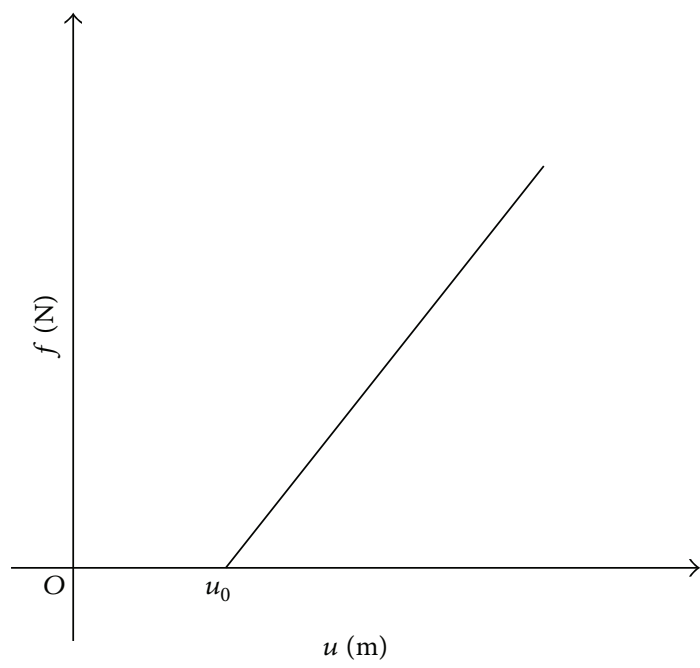

FIGURE 3: The relationship between force and displacement of nonlinear spring in the debonding area of CA mortar.

as shown in Figure 3 , where $u_{0}$ is the height of the debonding between track slab and CA mortar, $u$ is the compression of CA mortar, and $f$ is the force acting on the CA mortar. Assuming the debonding between CA mortar layer and slab to be continuous, the subgrade was simulated by uniform linear spring and damping elements.

Each rolling stock is deemed to be a vibration system of 7 rigid bodies ( 1 car body, 2 bogies, and 4 wheel-sets) linked by a suspension spring and damping. The car body and bogies have 2 degrees of freedom, bouncing and pitching. For the wheel-sets, only 1 degree of freedom, bouncing, was taken into consideration. Each rolling stock has 10 degrees of freedom. The wheel/rail normal force was determined by Hertz nonlinear elastic contact theory.

According to the explicit dynamic theory, the explicit central difference method of large general explicit dynamic analysis program LS-DYNA was used to solve the dynamic response equation [14].

\section{Calculation Parameters and Model Validation}

In this model, the rail type is CHN60, the fastener stiffness is $60 \mathrm{kN} / \mathrm{mm}$, and the space of fastener is $650 \mathrm{~mm}$. The slab of CRTS II slab ballastless track is connected by $6 \Phi 20 \mathrm{~mm}$ steel bar to ensure the longitudinal continuity of track. In the calculation model, the slab model is continuous, and the beam length of slab model is equal to the total length of calculation. The slab model used C55 grade concrete, and the bending stiffness was obtained according to the width of $1.275 \mathrm{~m}$ (consider half width of slab) and thickness of $0.2 \mathrm{~m}$. The CA mortar layer was simulated by linear spring and its stiffness was obtained according to the elasticity modulus of $7000 \mathrm{MPa}$. The bending stiffness was obtained according to the elasticity modulus of $7000 \mathrm{MPa}$, width of $1.625 \mathrm{~m}$ (consider half width of slab), and thickness of $0.3 \mathrm{~m}$. The bearing stiffness of subgrade is $75 \mathrm{MPa} / \mathrm{m}$ [15]. The train is

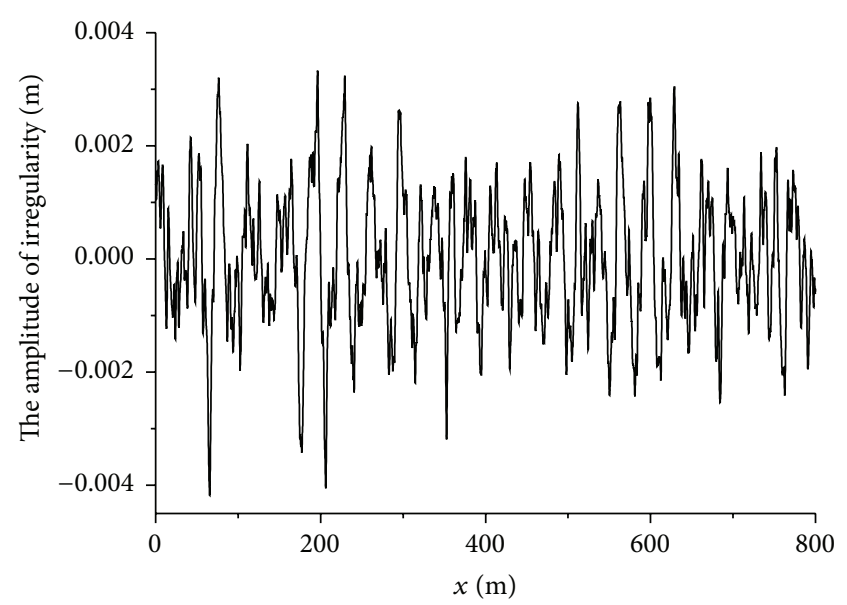

FIgURE 4: Time domain random irregularity sample of the Germanic low-disturbance spectrum.

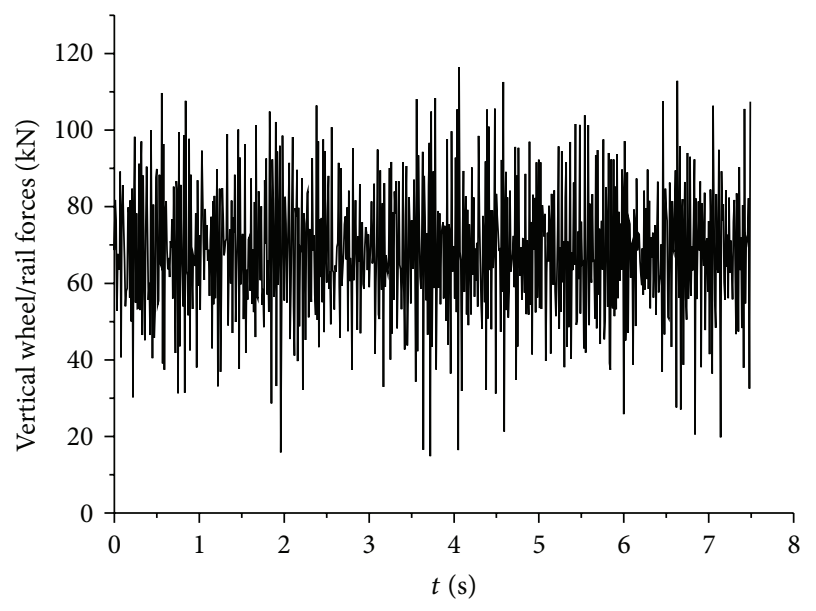

FIgURE 5: Time history of vertical wheel/rail forces.

CRH2 EMU, and the grouping-mode is 6 motor cars and 2 trailer cars. The high-speed train passes the subgrade section at the speed of $300 \mathrm{~km} / \mathrm{h}$. The wheel weight of motor car is $70 \mathrm{kN}$, and the wheel weight of trailer car is $58.5 \mathrm{kN}$. The calculated equivalent contact stiffness between wheel and rail are $1.193 \mathrm{GN} / \mathrm{m}$ of motor car and $1.131 \mathrm{GN} / \mathrm{m}$ of trailer car, respectively, based on the Hertz contact theory.

The track irregularity is Germanic low-disturbance spectrum. Figure 4 shows the time domain random irregularity sample calculated according to Chen and Zhai [16]. ( $x$ is the distance apart from the left of the model.)

In order to verify the validity of train-track-subgrade vertical vibration model in this paper, the dynamic response was calculated in the condition of complete track. Figure 5 shows the vertical wheel/rail forces' time history of back wheel-set, which belongs to back bogie of the fifth motor car. Figure 6 shows the time history of vertical displacement of rail in the middle of the model.

The maximum dynamic response of simulation calculated in this paper was compared with $\mathrm{Xu}$ and Cai [7], Nan [9], and the actual measurement of Beijing-Tianjin intercity 
TABLE 1: Comparison of measured data and calculated results.

\begin{tabular}{lccccc}
\hline Index & $\begin{array}{c}\text { Vertical wheel/rail } \\
\text { force/kN }\end{array}$ & $\begin{array}{c}\text { Displacement } \\
\text { of rail/mm }\end{array}$ & $\begin{array}{c}\text { The fulcrum reaction } \\
\text { force of rail/kN }\end{array}$ & $\begin{array}{c}\text { Displacement } \\
\text { of slab/mm }\end{array}$ & $\begin{array}{c}\text { Dynamic stress of CA } \\
\text { mortar layer/kPa }\end{array}$ \\
\hline This paper & 116.4 & 0.776 & 33.43 & 0.284 & 25.22 \\
Xu et al. [7] & 114.2 & 0.91 & 37.4 & 0.30 & 46.8 \\
Nan [9] & 112.225 & 0.847 & 31.35 & 0.358 & 40.389 \\
Zhang [17] & $109.2 \sim 120.5$ & $0.66 \sim 1.32$ & $47.8 \sim 49.2$ & $0.16 \sim 0.37$ & $\leq 45$ \\
\hline
\end{tabular}

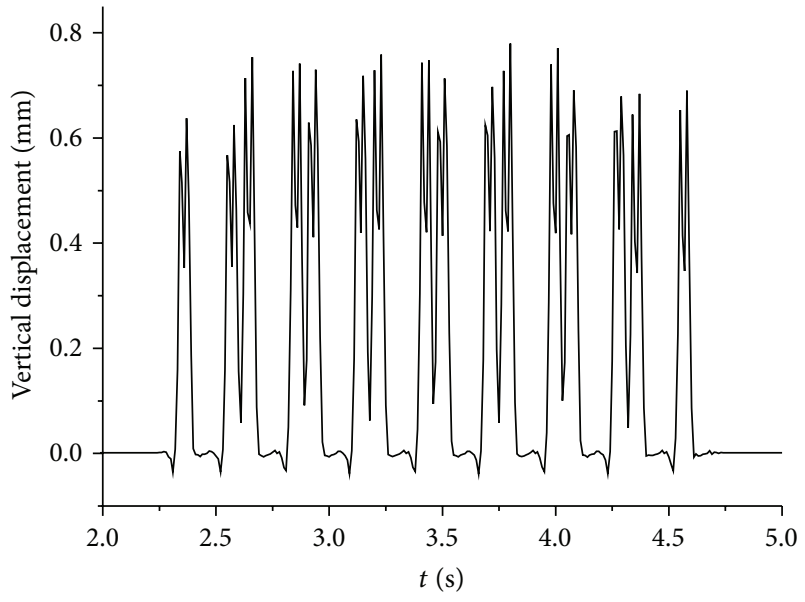

FIgURE 6: Time history of vertical displacement of rail.

railway [17]. The comparison result is given in Table 1. As shown in Table 1, the simulation results, each paper, and the actual measurement have good consistency, which has verified the reliability of the calculation model.

\section{Results and Analysis}

Using the calculation model, the dynamic responses of track system in different debonding conditions were analyzed by changing the relevant parameters. The place of debonding was installed in the middle of the model. The height of debonding is $3 \mathrm{~mm}$, and the lengths of debonding are $0 \mathrm{~m}$, $0.325 \mathrm{~m}, 0.65 \mathrm{~m}, 0.975 \mathrm{~m}, 1.3 \mathrm{~m}, 1.625 \mathrm{~m}, 1.95 \mathrm{~m}, 2.275 \mathrm{~m}$, $2.6 \mathrm{~m}, 2.925 \mathrm{~m}, 3.25 \mathrm{~m}$, and $3.9 \mathrm{~m}$.

5.1. Comparative Analysis with Debonding or Not. Figures 7 and 8 show the contrast curves of vertical relative displacement between slab and concrete supporting layer and the vertical vibration acceleration of slab in the middle model with no debonding and when debonding length is $0.65 \mathrm{~m}$. Figure 9 shows the contrast curves of vertical dynamic compressive stress of CA mortar near the debonding area with no debonding and when debonding length is $0.65 \mathrm{~m}$. The maximum dynamic responses of vehicle, track, and subgrade in the debonding area with debonding or not are shown in Table 2.

Comparing with no debonding, the vertical vibration acceleration of vehicle changes small when the train passes over the debonding region, which is shown in Table 2. The

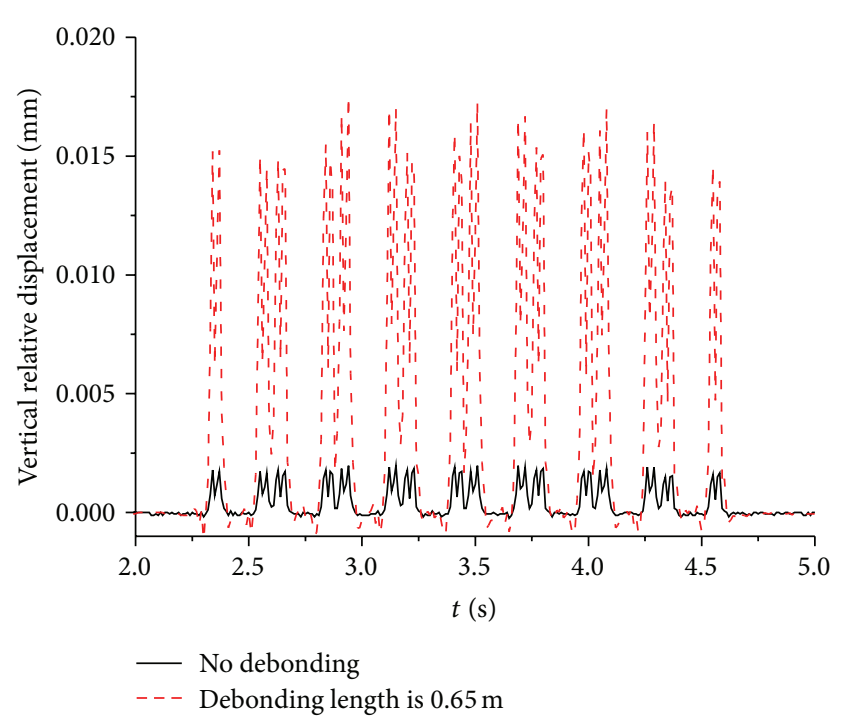

FIGURE 7: Time history of vertical relative displacement between slab and support layer.

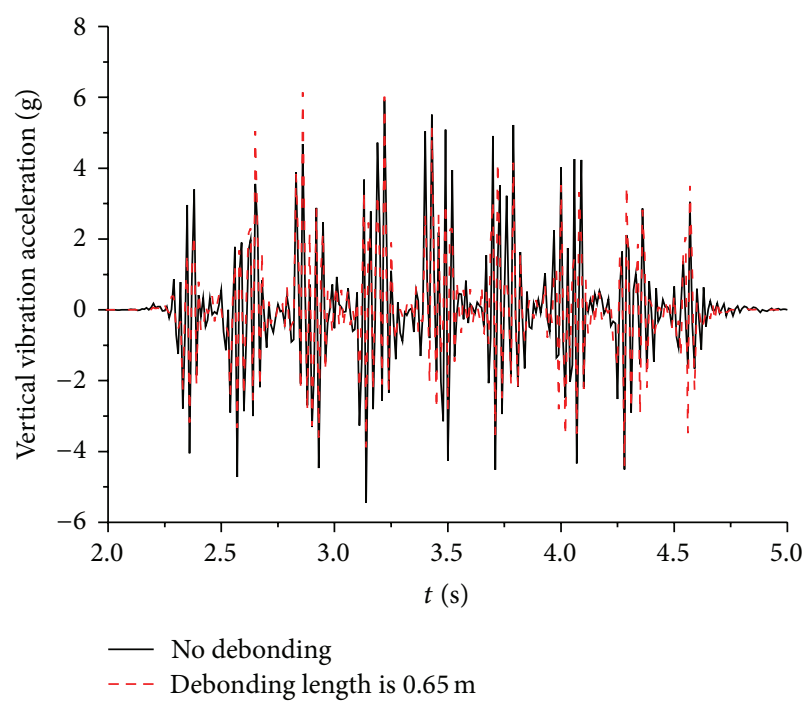

FIGURE 8: Time history of vertical vibration acceleration of slab.

debonding has no effect on the maximum dynamic response of vehicle system, the maximum and minimum of wheel/rail vertical force, when the debonding length of CA mortar layer is $0.65 \mathrm{~m}$. The random irregularity incentive still plays 


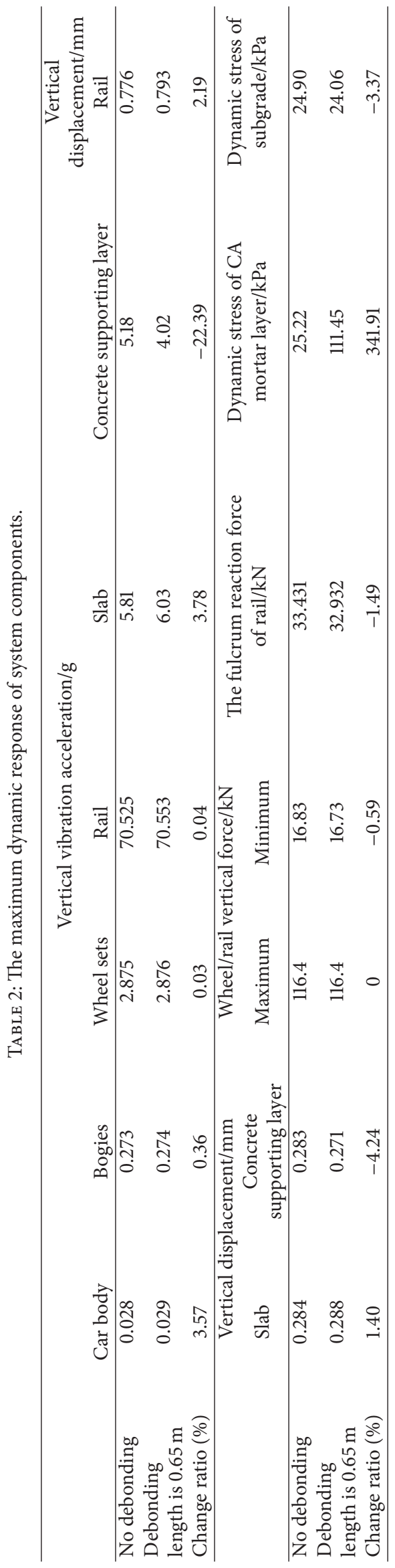




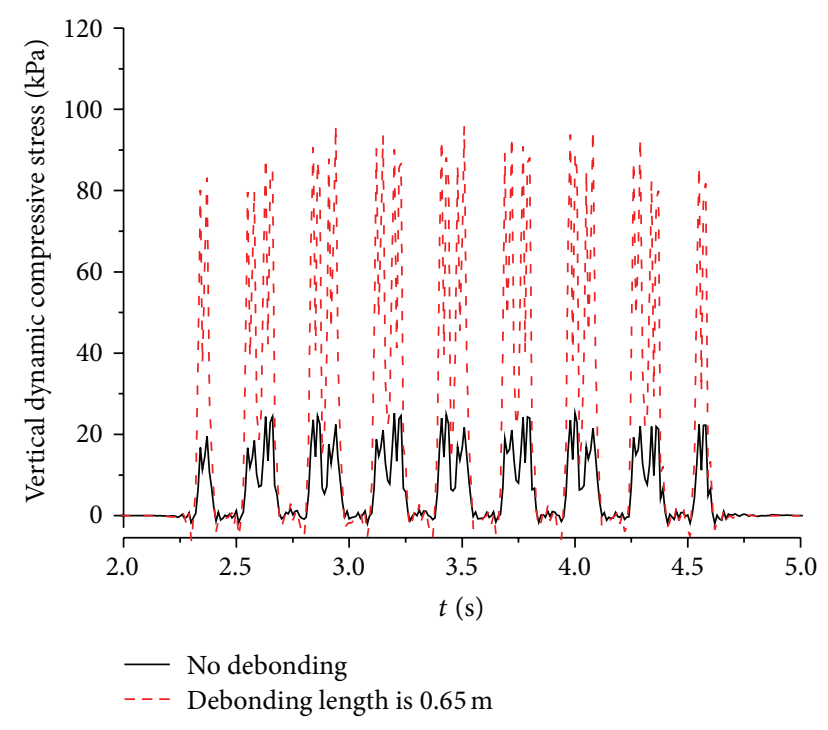

FIGURE 9: Time history of vertical dynamic compressive stress of CA mortar.

the leading role in the wheel/rail interaction and dynamic responses of vehicle system.

As shown in Figure 7 to Figure 9 and Table 2, the debonding of CA mortar has influence on the dynamic responses of track structure. The vertical displacement of rail and slab, the vertical vibration acceleration, and the relative displacement between slab and concrete supporting layer will increase if the CA mortar layer has debonding, while the dynamic compressive stress of CA mortar layer will increase rapidly, about 4.4 times higher. The debonding of CA mortar layer has influence on the train loading transfer to the concrete supporting layer and subgrade, so the displacement and vertical vibration acceleration of concrete supporting layer and the dynamic compressive stress of subgrade decrease when the CA mortar layer has debonding.

5.2. Influence of Debonding Length of CA Mortar Layer. In the middle of debonding area, the maximum vertical displacement of track structure in different lengths of debonding is shown in Figure 10. As shown in Figure 10, the maximum vertical displacements of rail and slab increase with the increase of debonding length. The vertical displacement of rail rises from $0.776 \mathrm{~mm}$ to $2.322 \mathrm{~mm}$ when the debonding length rises from $0 \mathrm{~m}$ to $3.9 \mathrm{~m}$, which increases about 3 times. The vertical displacement of slab rises from $0.284 \mathrm{~mm}$ to $2.006 \mathrm{~mm}$ when the debonding length rises from $0 \mathrm{~m}$ to $3.9 \mathrm{~m}$, about 7.08 times higher. But the maximum vertical displacement of concrete supporting layer decreases with the increase of debonding length. This shows that the forces transfer from rail to concrete supporting layer is smaller, and the debonding of CA mortar layer has advantages on the stress of concrete supporting layer and subgrade. The inflection points of rail, slab and concrete supporting layer's vertical displacement curves happen when the length of debonding is $1.95 \mathrm{~m}$.

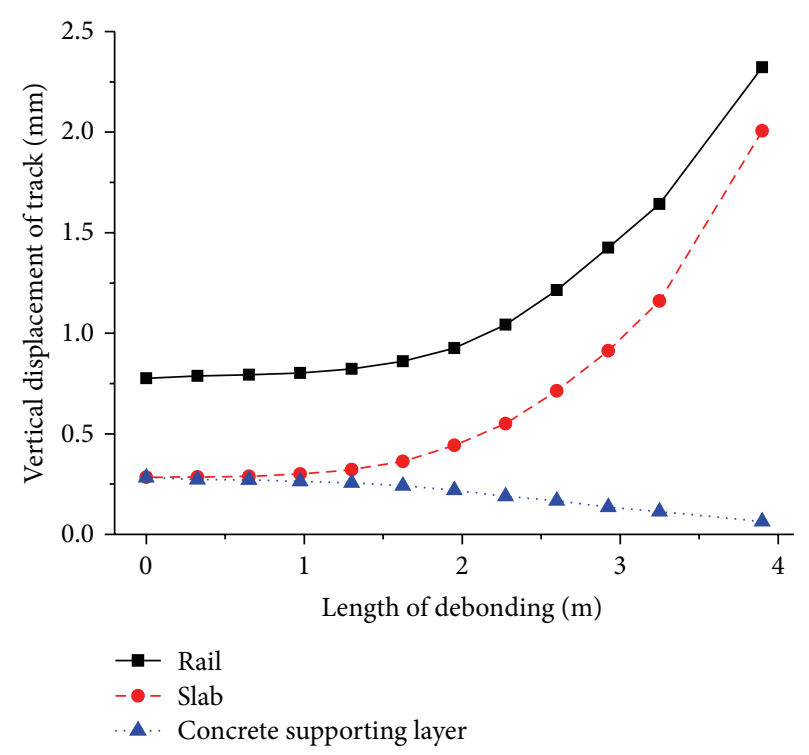

Figure 10: The vertical displacement of track structure.

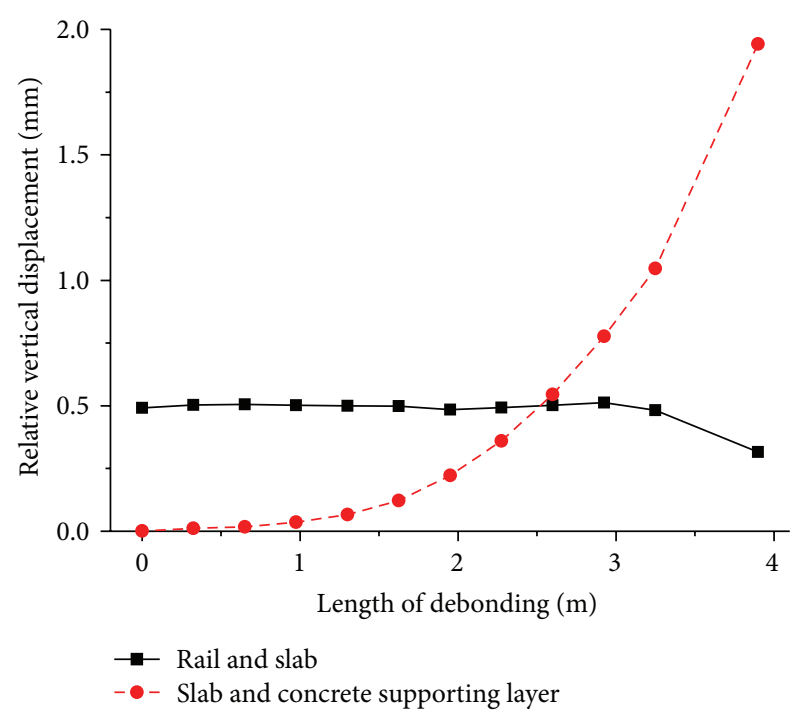

FIGURE 11: The vertical relative displacement of track structure.

In the middle of debonding area, the relative vertical displacement of track system in different debonding lengths is shown in Figure 11. As shown in Figure 11, the maximum vertical displacement of rail relative to slab changes a little with the increase of debonding length. This suggests that the increase of vertical displacement of rail is mainly due to the increase of the vertical displacement of slab. The vertical displacement of slab relative to the concrete supporting layer increases with the increase of debonding length. The relative displacement rises from $0.001 \mathrm{~mm}$ to $1.942 \mathrm{~mm}$ when the debonding length rises from $0 \mathrm{~m}$ to $3.9 \mathrm{~m}$, because the debonding of CA mortar layer reduces the transfer of train loading.

Figure 12 shows the vertical vibration acceleration of slab changing with the debonding length in the middle of the 
TABLE 3: The compressive stress of CA mortar contrast between cavity and no cavity near the cavity area $(\mathrm{kPa})$.

\begin{tabular}{lccccc}
\hline \multirow{2}{*}{ Working condition } & \multicolumn{5}{c}{ Length of debonding/m } \\
& 0.325 & 0.65 & 0.975 & 1.3 & 1.925 \\
\hline No debonding & 29.45 & 25.22 & 32.231 & 35.688 & 32.086 \\
Debonding & 66.667 & 111.454 & 142.282 & 212.097 & 259.316 \\
Increase ratio (\%) & 126.37 & 341.927 & 341.44 & 494.309 & 708.19 \\
\hline \multirow{2}{*}{ Working condition } & & \multicolumn{5}{c}{ Length of debonding/m } & 379.704 \\
& 2.275 & 2.6 & 2.925 & 3.25 & 3.9 \\
No debonding & 27.231 & 29.341 & 27.921 & 24.427 & 32.879 \\
Debonding & 455.669 & 502.134 & 589.987 & 657.091 & 839.534 \\
Increase ratio (\%) & 1573.34 & 1611.37 & 2013.06 & 2590.02 & 2453.40 \\
\hline
\end{tabular}

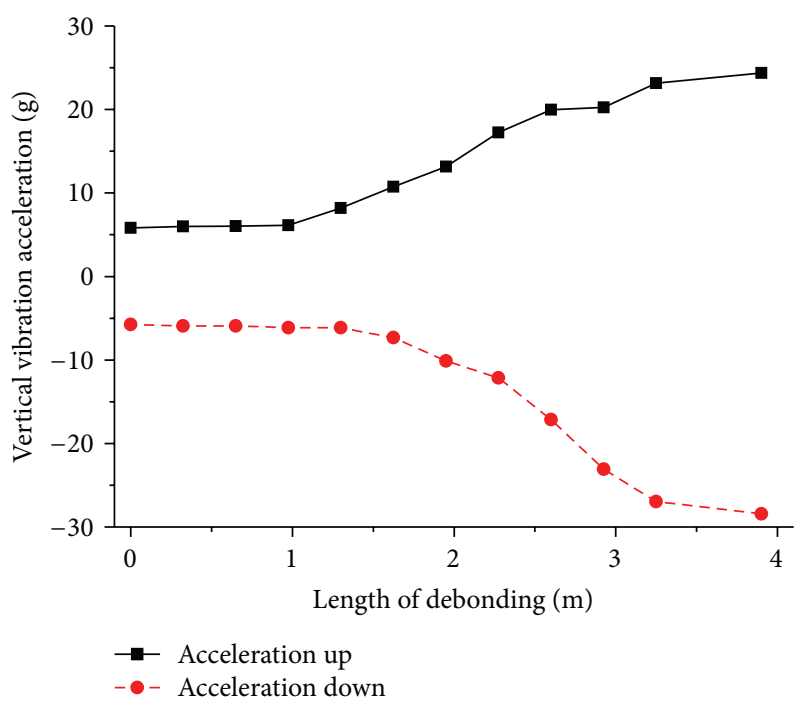

FIGURE 12: The vertical acceleration of slab.

debonding region. As shown in Figure 12, the vertical vibration accelerations up and down increase with the increase of debonding length. When the debonding length is $3.9 \mathrm{~m}$, the vertical vibration accelerations up and down increase 4.2 times and 4.95 times, respectively, compared with no debonding. The vertical vibration acceleration of slab exceeds $10 \mathrm{~g}$ when the debonding length of CA mortar exceeds $1.95 \mathrm{~m}$.

The vertical dynamic compressive stress of CA mortar layer near the debonding region compared with no debonding is shown in Table 3. Because of the difference of track irregularity in the whole model, the vertical dynamic compressive stress of CA mortar layer varies in different location and has little difference. As shown in Table 3, the dynamic compressive stress of CA mortar layer in the same place increases rapidly with the increase of debonding length. When the length of debonding is $3.9 \mathrm{~m}$, the dynamic compressive stress of CA mortar layer is $839.534 \mathrm{kPa}$, which increases by 15 times. The CA mortar layer will be damaged sequentially with the repeating actions of train loading; therefore, the debonding will increase. This is a vicious cycle, leading to a shortening of the ballastless track's service life.

According to the analysis above, the inflection point of vertical displacement in different places of track system happens when the length of debonding of CA mortar exceeds $1.95 \mathrm{~m}$, the vertical vibration acceleration of slab exceeds $10 \mathrm{~g}$, and the dynamic compressive stress of CA mortar increases by 15 times. So the debonding length of CA mortar between slab and concrete supporting layer of CRTS II slab ballastless track should be no more than $1.9 \mathrm{~m}$.

\section{Conclusions}

A vertical coupling vibration model for vehicle-tracksubgrade was established according to the finite element method and the wheel/rail coupling dynamics theory. The effects of different debonding length on dynamic responses of vehicle and track structure in the debonding region were analyzed. Although the analysis model has its limitations, as the effect of the debonding of CA mortar layer along the transverse of slab on the dynamic responses of track which cannot be analyzed, the following conclusions can be drawn.

(1) The debonding length has little influence on the dynamic responses of vehicle system, and it has no effect on the comfort of driving, because the CRTS II slab ballastless track is continuous.

(2) Debonding of CA mortar under the slab has a significant impact on the vibration of slab as well as the dynamic compressive stress of CA mortar near the debonding region. The vertical vibration acceleration of slab increases by 4.95 times and the dynamic compressive stress of CA mortar layer increases by 15 times when the debonding length reaches $3.9 \mathrm{~m}$.

(3) The debonding of CA mortar layer decreases the train loading transfer to the substructure, which leads to a decrease of the displacement of concrete supporting layer and the dynamic compressive stress under the debonding region.

(4) Because of the debonding of CA mortar layer, the vertical displacement of rail and slab increases, and the dynamic compressive stress of CA mortar layer increases rapidly. Train loading causes "debonding of CA mortar-CA mortar deterioration-increase of debonding length," which is a vicious cycle, leading to a shortening of the ballastless track's service life. For CRTS II type slab ballastless track, once the length of debonding reaches $1.95 \mathrm{~m}$, the mortar debonding should be repaired immediately. 


\section{Conflict of Interests}

The authors declare that there is no conflict of interests regarding the publication of this paper.

\section{Acknowledgments}

This research was supported by the National Basic Research Program of China (2013CB036202), the National Science Foundation of China (51008258, 51208431), and Railway Ministry Science and Technology Research and Development programs (2010G006-B).

\section{References}

[1] E. Coenraad, "Recent development in slab track," European Railway Review, vol. 9, no. 2, pp. 81-85, 2003.

[2] X. H. Zeng, Y. J. Xie, and D. H. Deng, "Conductivity behavior of fresh CA mortar and its relationship with the fluidity properties," Construction and Building Materials, vol. 36, pp. 890-894, 2012.

[3] M. Shigeru, T. Hideyuki, U. Masao, and F. Yasuto, "The mechanism of railway tracks," Japan Railway and Transportation Review, vol. 15, no. 3, pp. 38-45, 1998.

[4] A. Katsuoshi, "Development of slab tracks for Hokuriku Shinkansen line," Quarterly Report of RTRI, vol. 42, no. 1, pp. 35-41, 2001.

[5] O. Murata, "Overview of recent structure technology R\&D at RTRI," Quarterly Report of RTRI, vol. 44, no. 4, pp. 133-135, 2003.

[6] J. Xiang, D. He, and Q. Y. Zeng, "Effect of cement asphalt mortar disease on dynamic performance of slab track," Journal of Central South University, vol. 40, no. 3, pp. 791-796, 2009 (Chinese).

[7] P. Xu and C. B. Cai, "Dynamic analysis of longitudinally connected ballastless track on earth subgrade," Journal of Southwest Jiaotong University, vol. 46, no. 2, pp. 189-194, 2011 (Chinese).

[8] X. L. Song and W. M. Zhai, "Dynamic Stress Distribution of the infrastructure of CRTS II slab ballastless track under high speed moving load," China Railway Science, vol. 33, no. 4, pp. 1-7, 2012 (Chinese).

[9] H. Y. Nan, Analysis on the Dynamic Characteristics of CRTS II Type Slab Ballastless Track on Subgrade and the Parametric Study, Lanzhou Jiaotong University, Lanzhou, China, (Chinese).

[10] W. M. Zhai, K. Y. Wang, and C. B. Cai, "Fundamentals of vehicle-track coupled dynamics," Vehicle System Dynamics, vol. 47, no. 11, pp. 1349-1376, 2009.

[11] W. M. Zhai and X. Sun, "A detailed model for investigating vertical interaction between railway vehicle and track," Vehicle System Dynamics, vol. 23, supplement, pp. 603-615, 1994.

[12] G. Chen and W. M. Zhai, "A new wheel/rail spatially dynamic coupling model and its verification," Vehicle System Dynamics, vol. 41, no. 4, pp. 301-322, 2004.

[13] W. M. Zhai, C. B. Cai, and S. Z. Guo, "Coupling model of vertical and lateral vehicle/track interactions," Vehicle System Dynamics, vol. 26, no. 1, pp. 61-79, 1996.

[14] P. Li, X. Liu, and X. Fu, "Analyses of vertical dynamic properties of ballastless track based on LS-DYNA," in Proceedings of the 3rd International Conference on Transportation Engineering, pp. 1755-1760, Chengdu, China, 2011.
[15] P. Wang, H. Xu, R. Chen, and J. M. Xu, "Effects analysis of cracking of CRTS II slab track on subgrade," Journal of Southwest Jiaotong University, vol. 47, no. 6, pp. 929-934, 2012 (Chinese).

[16] G. Chen and W. M. Zhai, "Numerical simulation of random process about railway track irregularity," Journal of Southwest Jiaotong University, no. 2, pp. 138-142, 1999 (Chinese).

[17] S. G. Zhang, Beijing-Tianjin Intercity High-Speed Rail System Debugging Techniques, China Railway Publishing House, Beijing, China, 2008, (Chinese). 

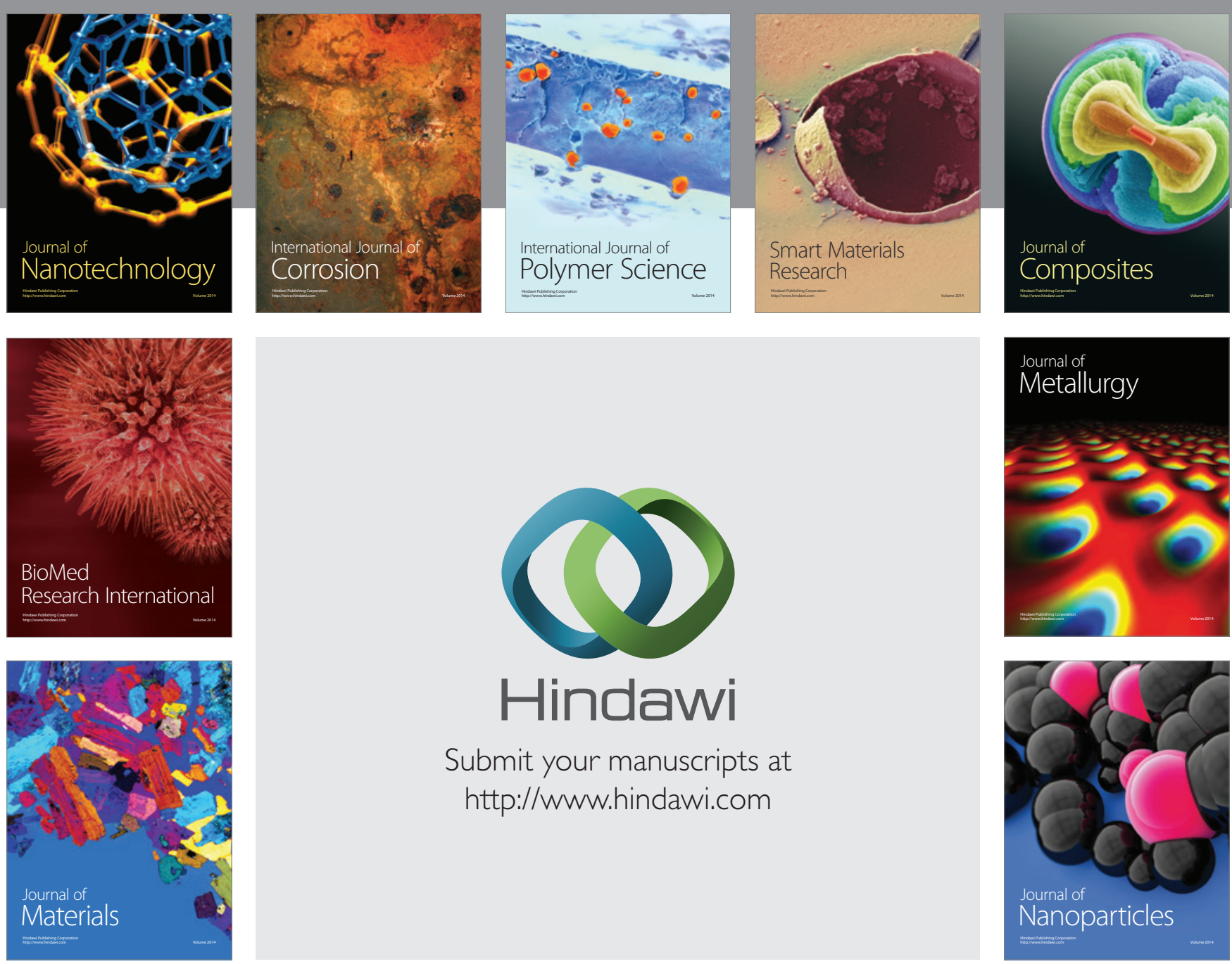

Submit your manuscripts at http://www.hindawi.com
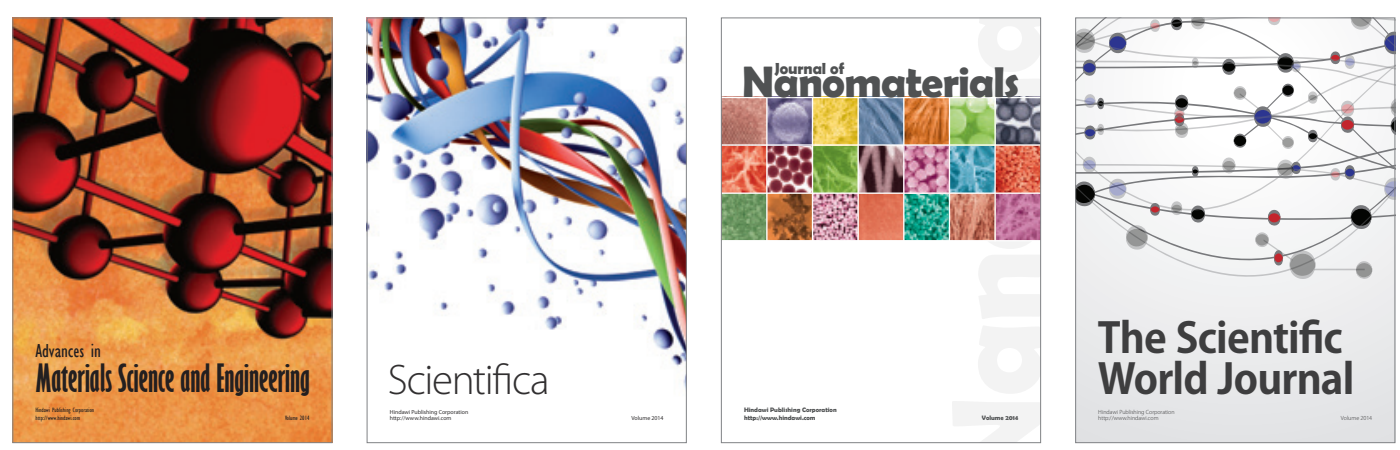

\section{The Scientific World Journal}
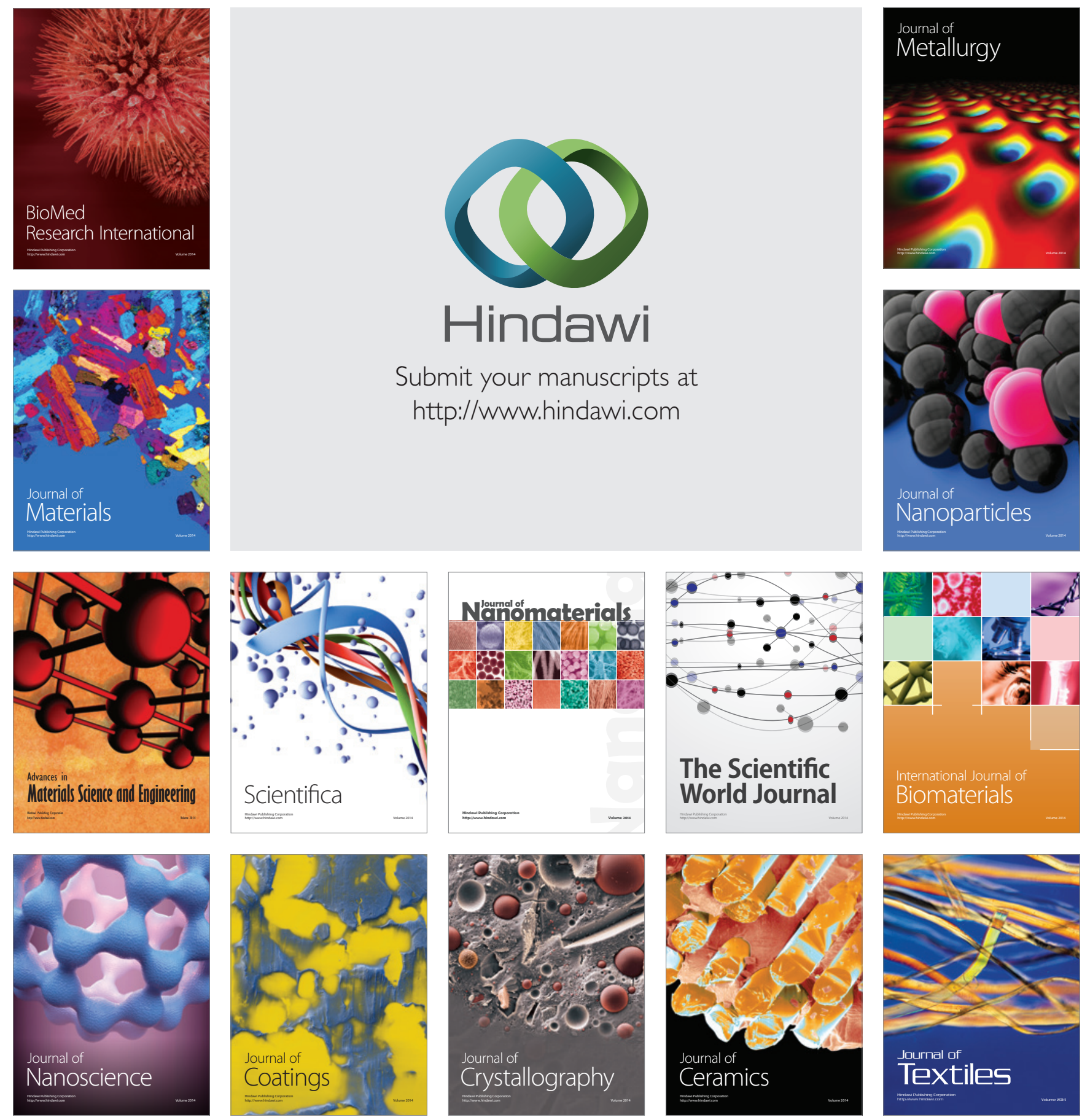